\title{
BMJ Open Cross-sectional survey describing general practitioners' absolute cardiovascular disease risk assessment practices and their relationship to knowledge, attitudes and beliefs about cardiovascular disease risk in Queensland, Australia
}

\author{
Kim Greaves (D) , ${ }^{1}$ Anita Smith, ${ }^{2}$ Jason Agostino, ${ }^{1}$ Kuhan Kunarajah, ${ }^{2}$ \\ Tony Stanton, ${ }^{2}$ Rosemary Korda ${ }^{1}$
}

To cite: Greaves K, Smith A, Agostino J, et al. Crosssectional survey describing general practitioners' absolute cardiovascular disease risk assessment practices and their relationship to knowledge, attitudes and beliefs about cardiovascular disease risk in Queensland, Australia. BMJ Open 2020;10:e033859. doi:10.1136/ bmjopen-2019-033859

- Prepublication history and additional material for this paper are available online. To view these files, please visit the journal online (http://dx.doi. org/10.1136/bmjopen-2019033859).

Received 31 August 2019 Revised 12 May 2020 Accepted 29 May 2020

Check for updates

(C) Author(s) (or their employer(s)) 2020. Re-use permitted under CC BY-NC. No commercial re-use. See rights and permissions. Published by BMJ.

For numbered affiliations see end of article.

Correspondence to Professor Kim Greaves; kim.greaves@health.qld.gov.au

\section{ABSTRACT}

Objectives To describe general practitioners' (GPs') absolute cardiovascular disease risk (ACVDR) self-reported assessment practices and their relationship to knowledge, attitudes and beliefs about ACVDR.

Design Cross-sectional survey with opportunistic sampling (October-December 2017).

Setting Sunshine Coast region, Queensland, Australia. Participants $111 \mathrm{GPs}$ responded to the survey.

Primary and secondary outcome measures Proportion of GPs reporting a high ( $\geq 80 \%)$ versus moderate $(60 \%$ $79 \%) /$ low $(<60 \%)$ percentage of eligible patients receiving ACVDR assessment; proportion agreeing with statements pertaining to knowledge, attitudes and beliefs about ACVDR and associations between these factors. Results Of the 111 respondents, $78 \%$ reported using the Australian ACVDR calculator; 45\% reported high, 25\% moderate and 30\% low ACVDR assessment rates; > $>5 \%$ reported knowing how to use ACVDR assessment tools, believed assessment valuable and were comfortable with providing guideline-recommended treatment. Around half believed patients understood the concept of high risk and were willing to adopt recommendations. High assessment rates (vs moderate/low) were less likely among older GPS ( $\geq 45$ vs $\leq 34$ years, age-adjusted and sex-adjusted OR (aOR) $0.36,95 \% \mathrm{Cl} 0.12$ to 0.97$)$. Those who answered knowledge-based questions about the guidelines incorrectly had lower assessment rates, including those who answered questions on patient eligibility (aOR 0.13 , $95 \% \mathrm{Cl} 0.02$ to 1.11). A high assessment rate was more likely among GPs who believed there was sufficient time to do the assessment (aOR $3.79,95 \% \mathrm{Cl} 1.23$ to 11.61) and that their patients were willing to undertake lifestyle modification (aOR 2.29, 95\% Cl 1.02 to 5.15). Over $75 \%$ of GPs agreed better patient education, nurseled assessment and computer-reminder prompts would enable higher assessment rates.

Conclusions Although the majority of GPs report using the ACVDR calculator when undertaking a CVD
Strengths and limitations of this study

- First survey to assess the proportion of eligible patients undergoing absolute cardiovascular disease risk score assessment as self-reported by general practitioners (GPs).

- Ability to examine the association between CVD assessment rates by GPs, and GP knowledge, attitudes and beliefs about CVD risk.

- Limited to GPs in Queensland, Australia.

- Relies on self-reporting by GPs rather than objective measures.

risk assessment, there is a need to increase the actual proportion of eligible patients undergoing ACVDR assessment. This may be achieved by improving GP assessment practices such as GP and patient knowledge of CVD risk, providing sufficient time and nurse-led assessment.

\section{INTRODUCTION}

Cardiovascular disease (CVD) is the leading cause of morbidity and mortality in Australia, and its prevention is a national health priority. ${ }^{1-3}$ A large proportion of CVD is preventable by appropriate population-level interventions and individual management of risk. ${ }^{4}$ The potential benefit of treatments to reduce CVD events are closely related to an individual's absolute or total cardiovascular disease risk (ACVDR). ${ }^{56}$

The National Vascular Disease Prevention Alliance (NVDPA) of Australia guidelines recommend calculating risk using the ACVDR Score. ${ }^{7}$ Factors included in the risk score are age, gender, smoking, systolic blood pressure, 
total cholesterol to high density lipoproten (HDL) ratio and diabetes. A 5-year risk for the development of CVD is calculated and categorised according to whether a patient has low $(<10 \%)$, moderate $(10 \%-15 \%)$ or high $(>15 \%)$ risk. Certain groups of patients are automatically considered at high risk and do not need to have their risk calculated. For example, those patients with known CVD, who are diabetic and over 60 years of age, or who have a cholesterol equal to $7.5 \mathrm{mmol} / \mathrm{L}$ or higher. A version of the risk score calculator is usually embedded in the general practitioner (GP) patient management software or can be accessed directly at the Heart Foundation's website. ${ }^{8}$ Patients without prior CVD and a high ACVDR score, or moderate risk with additional risk factors, are recommended to receive lifestyle modification advice and be prescribed both lipid and blood pressure-lowering therapy. However, most Australians at high CVD risk are not receiving recommended combination therapy. ${ }^{9}$ This treatment gap is likely due to multiple factors, including lack of assessment by GPs. ${ }^{9-12}$ Studies examining ACVDR assessment in general practice report anywhere between $17 \%$ and $85 \%$ of GPs use risk assessment tools. ${ }^{9} 1213$ However, the actual proportion of eligible patients that have their ACVDR calculated by their GPs is unknown.

The barriers to risk assessment faced by GPs, particularly those based in Europe, are well described..$^{11}{ }^{13}$ These include lack of time to undertake risk assessment, incentives and GP-patient knowledge regarding cardiovascular risk. However, whether these known barriers or other GP characteristics are associated with the proportions of eligible patients undergoing ACVDR score assessment self-reported by GPs in Australia are unknown.

The aims of this study were to describe Australian GPs' self-reported ACVDR assessment practices, and knowledge, attitudes and beliefs about ACVDR; examine associations between ACVDR assessment rates and GP characteristics, and knowledge, attitudes and beliefs about ACVDR; and report on GP ratings of potential barriers and enablers of ACVDR assessment.

\section{METHODS}

\section{Study design and population}

We undertook a cross-sectional survey with opportunistic sampling of participants. During October-December 2017, the survey was made available to actively practising GPs on the Sunshine Coast region of Queensland in electronic and hard copy format. Distribution lists of GP practices were obtained from the Primary Healthcare Network. The web-based survey was also placed on a Survey Monkey platform, and this link was circulated via email and on social media to GPs. Hard copies of the surveys were also provided to GPs in person to complete the survey at their workplace. Additionally, the survey was distributed at GP education events.

The total number of GPs approached was not measured. Online sharing of the survey web link by GPs meant that practitioners outside the Sunshine Coast region also completed the survey and, provided they were from Queensland, were accepted into the study.

\section{Survey questionnaire}

The survey questionnaire was developed from information in the existing literature, previous surveys (online supplementary figure 1) as well from the direct experiences expressed by GPs to the investigators. ${ }^{12} 14-18$ This was then refined several times following consultation with two cardiologists (KG and TS), three GPs, two primary healthcare network staff, a senior member of the Heart Foundation and an epidemiologist (RK). The survey used closed-ended questions to collect self-reported information on GP and workplace characteristics (questions 1-8, 16-18) and on perceived ACVDR knowledge (questions 9 and 10) and assessment practices, including a question on the proportion of eligible patients assessed (response categories: all (ie, $100 \%$ ), $80 \%-99 \%, 60 \%-79 \%, 40 \%-59 \%$, $30 \%-39 \%, 1 \%-19 \%$, never $(0 \%)$, 'I do not assess total CVD risk in general', 'I assess treat each factor individually', 'I am unsure who an eligible patient is for total CVD disease risk assessment' and 'Other'). For information on attitudes, beliefs (question 21.1, 21.4-21.15 and 22.13) and further perceived knowledge (questions 13-15, 20, 21.1 and 21.2) in relation to ACVDR risk assessments, GPs were asked to rate their responses to 15 separate items relating to GP, patient and organisational/structural factors, using a 7-point Likert scale ranging from 'strongly disagree' to 'strongly agree'. In addition, GPs were asked to rate potential barriers and enablers to performing ACVDR assessments, using a 7-point Likert scale (question 22.1-22.12). The full survey can be accessed in the online supplement (online supplementary figure 1). Information on the time taken explaining the meaning of the risk score to patients (question 23) and also referral practices (question 24) were also recorded.

\section{Analysis}

Assessment practices were described in terms of number and proportion (\%) of GPs. For the analysis, we dichotomised assessment rates-the main outcome variableinto high ( $\geq 80 \%$ eligible patients receiving ACVDR assessment) versus moderate $(60 \%-79 \%) /$ low $(<60 \%)$ and proportion agreeing into yes (includes those who reported 'strongly agree', 'agree' and 'agree somewhat') or no ('strongly disagree', 'disagree', 'disagree somewhat' or 'undecided') for statements pertaining to knowledge, attitudes and beliefs about ACVDR and proposed barriers and enablers. We used logistic regression to quantify the association between GP characteristics, knowledge, attitudes and beliefs and ACVDR assessment rates, reporting both crude and age-adjusted and sex-adjusted ORs with 95\% CIs. For several of the variables on GP characteristics, response categories were combined due to small numbers.

A sensitivity analysis was performed whereby the assessment rate variable was recategorised as high/moderate 
combined (ACVDR assessed in $\geq 60 \%$ of eligible patients) versus low. Stata V.15.1 was used for statistical analyses.

A verbal and/or written explanation of the purposes of the survey was given to GPs prior to completing the survey. No identifying details of participants were recorded. All data reported were aggregate. This study was considered to be low risk. The ethics committees did not require a consent form to be signed by participants as completion of the survey was considered as consent to participate.

\section{Patient and public involvement}

Patients and the public were not involved in the design, conduct, reporting or dissemination of our research.

\section{RESULTS}

\section{GP characteristics and ACVDR assessment practices}

A total of 111 GPs responded to the survey of whom $78(70 \%)$ were based on the Sunshine Coast, which represents $13 \%$ of the approximately 600 GPs registered on the Sunshine Coast. Fifty-three per cent were male and $43 \%$ were aged $\geq 45$ years (see table 1 ).

Nearly all GPs $(108 / 111,96 \%)$ reported being aware of ACVDR assessment and around half (46\%) had heard of the Guidelines for the Management of Absolute CVD Disease Risk as issued by the NVDPA.

Fifty (45\%, 95\% CI 36\% to 55\%) GPs were high assessors with $19(17 \%)$ reporting assessing $100 \%$ of eligible individuals; $28(25 \%, 95 \%$ CI $17 \%$ to $34 \%)$ GPs were moderate assessors and $33(30 \%, 95 \% 21 \%$ to $39 \%)$ low assessors. Within the low assessment group, six (5\% of all GPs respondents) assessed $<20 \%$ eligible patients; six $(5 \%)$ were unsure of who an eligible patient was, did not assess CVD risk or treated risk factors individually; overall. this was equivalent to 1 in 10 GPs. The eight $(7 \%)$ written responses in the 'Other' section were categorised as low assessors. The full range of assessment rates is shown in table 2. Most GPs (78\%) used the Australian ACVDR calculator, either alone $(72 \%)$ or in combination with another risk system $(6 \%)$, with a small minority using Q-risk (4\%). Nine per cent used either their own clinical judgement, did not use a risk score system or did not know. The remaining $(9 \%)$ used other algorithms. Nearly half $(48 \%)$ of GPs spend between 5 min and 9 min explaining the score, $28 \% 0-4 \mathrm{~min}$ and $15 \% 10-15 \mathrm{~min}$.

Referral patterns of GPs for lifestyle modification are shown in online supplementary table 1 . The most commonly referred to practitioners are dietitians (76\%), exercise physiologists $(68 \%)$ and creation of a chronic disease management plan (60\%).

Table 3 shows crude and age-adjusted sex-adjusted ORs for the association between GP characteristics and high assessment rates. Increasing age and years worked were associated with lower assessment rates, but only age remained associated in the adjusted analysis, with older GPs less likely to assess a high proportion of
Table 1 GP characteristics for high and moderate/low assessors

\begin{tabular}{|c|c|c|c|}
\hline & $\begin{array}{l}\text { High } \\
\text { assessors } \\
\%(n), \\
n=50\end{array}$ & $\begin{array}{l}\text { Moderate/low } \\
\text { assessors } \\
\%(n), n=61\end{array}$ & $\begin{array}{l}\text { Total } N \\
(\%), n=111\end{array}$ \\
\hline \multicolumn{4}{|l|}{ Age range (years) } \\
\hline$\leq 34$ & $26(13)$ & $16(10)$ & $23(21)$ \\
\hline $35-44$ & $46(23)$ & $28(17)$ & $40(36)$ \\
\hline$\geq 45$ & $28(14)$ & $57(34)$ & $48(43)$ \\
\hline \multicolumn{4}{|l|}{ Gender } \\
\hline Female & $62(31)$ & $46(28)$ & $59(45)$ \\
\hline Male & $36(18)$ & $52(32)$ & $50(53)$ \\
\hline $\begin{array}{l}\text { Intersex/ } \\
\text { indeterminate }\end{array}$ & $50(1)$ & $50(1)$ & $2(2)$ \\
\hline \multicolumn{4}{|l|}{ Years worked as GP } \\
\hline$\leq 5$ & $44(22)$ & $21(13)$ & $35(32)$ \\
\hline $6-15$ & $30(15)$ & $36(22)$ & $37(33)$ \\
\hline$\geq 16$ & $26(13)$ & $43(26)$ & $39(35)$ \\
\hline \multicolumn{4}{|l|}{ Employment status } \\
\hline Full time & $60(30)$ & $61(37)$ & $67(60)$ \\
\hline Part time/casual & $40(20)$ & $39(24)$ & $44(40)$ \\
\hline \multicolumn{4}{|c|}{ Hours worked per week } \\
\hline$\leq 29$ & $16(8)$ & $18(11)$ & $19(17)$ \\
\hline 30-39 & $40(20)$ & $20(12)$ & $32(29)$ \\
\hline 40 & $20(10)$ & $18(11)$ & 21 (19) \\
\hline$\geq 41$ & $24(12)$ & $44(27)$ & 39 (35) \\
\hline \multicolumn{4}{|c|}{ Number of GPs in workplace } \\
\hline$<10$ & $62(31)$ & $59(36)$ & $67(60)$ \\
\hline$\geq 10$ & $30(15)$ & $38(23)$ & $38(34)$ \\
\hline $\begin{array}{l}\text { Work at }>1 \\
\text { practice }\end{array}$ & $8(4)$ & $4(2)$ & $6(5)$ \\
\hline \multicolumn{4}{|l|}{ Role in practice } \\
\hline $\begin{array}{l}\text { Registrar/in } \\
\text { training }\end{array}$ & $20(10)$ & $8(5)$ & $15(14)$ \\
\hline $\begin{array}{l}\text { Contractor/ } \\
\text { sessional/ } \\
\text { retainer/salaried }\end{array}$ & $66(33)$ & $70(43)$ & $76(68)$ \\
\hline Partner/principal & $14(7)$ & 21 (13) & 20 (18) \\
\hline
\end{tabular}

High assessors assessed CVD risk scores in $\geq 80 \%$ of their eligible patients. Moderate and low assessors assessed absolute CVD risk in $\leq 79 \%$ of their eligible patients. Total questionnaires completed 111. No missing data.

CVD, cardiovascular disease; GP, general practitioner.

patients $(\mathrm{aOR} \geq 45 \mathrm{vs} \leq 34$ years $=0.36,95 \%$ CI 0.12 to $0.97)$.

GP knowledge, attitudes and beliefs about ACVDR assessment and associations with assessment rates

Around 1 in 10 GPs (11\%) were not aware that ACVDR assessment should be performed in all eligible patients. 


\begin{tabular}{|c|c|c|}
\hline $\begin{array}{l}\text { In what percentage of eligible } \\
\text { patients do you assess total } \\
\text { CVD risk? }\end{array}$ & Number & Per cent \\
\hline $100 \%$ & 19 & 17 \\
\hline $80 \%-99 \%$ & 31 & 28 \\
\hline $60 \%-79 \%$ & 28 & 25 \\
\hline $40 \%-59 \%$ & 6 & 5 \\
\hline $20 \%-39 \%$ & 9 & 8 \\
\hline $1 \%-19 \%$ & 5 & 5 \\
\hline I do not assess CVD risk & 2 & 2 \\
\hline $\begin{array}{l}\text { I assess and treat each risk } \\
\text { factor individually }\end{array}$ & 2 & 2 \\
\hline $\begin{array}{l}\text { I am unsure who an eligible } \\
\text { patient is }\end{array}$ & 1 & 1 \\
\hline Other & 8 & 7 \\
\hline Total & 111 & 100 \\
\hline
\end{tabular}

'Other': written text responses from GPs, which were a combination of assessing each factor individually and using ACVDR risk calculator; different age category and $>1$ risk factor. ACVDR, absolute cardiovascular disease risk; CVD, cardiovascular disease; GPs, general practitioners.

GPs were asked how regularly they should reassess an individual's ACVDR if low, moderate or high risk according to NVDPA risk guidelines (7). The proportions of GPs that correctly answered were $13(11 \%), 56(42 \%)$ and 12 $(11 \%)$, respectively. GPs were asked about the age range at which patients became eligible for ACVDR assessment: $48(43 \%)$ answered correctly and the remaining were incorrect $(10 \%)$ or did not respond $(47 \%)$.

A high proportion of GPs $(>85 \%)$ reported they knew how to use ACVDR assessment tools, how to proceed after assessment, believed ACVDR assessment valuable and were comfortable with prescribing dual medications for high and moderate risk patients (table 4). A third of GPs agreed ACVDR assessment was accurate in the elderly, and one in eight GPs referred patients for a calcium score. The questions relating to GP perceived knowledge, attitudes and beliefs can also be found in table 4 .

Around half of GPs believed their patients understood the concept of high risk and would adhere to medications $(59 \%)$ and would participate in lifestyle modification services $(52 \%)$. The majority of GPs $(77 \%)$ agreed there was sufficient time to undertake ACVDR assessment during a routine appointment, while $29 \%$ reported opportunistic assessments were difficult. Almost 40\% of GPs agreed there was a lack of incentives to undertake ACVDR assessment, and 20\% reported cholesterol results were not available in those who needed ACVDR assessment.

Several factors relating to GPs' self-reported perceived knowledge, attitudes and beliefs were associated with assessment rates. Lack of knowledge that assessment was recommended in all eligible patients was associated with lower assessment rates (OR $0.09,95 \%$ CI 0.1 to 0.76 ; aOR $0.13,95 \%$ CI 0.02 to 1.11 ). A high assessment rate (vs moderate/low) was also associated with knowledge of how to proceed after the ACVDR assessment (OR 8.47, 95\% CI 1.03 to 69.38 ; aOR $7.35,95 \%$ CI 0.7671 .35 ). A high (vs moderate/low) assessment rate was associated with belief that: there was sufficient time to do the assessment (aOR 3.79, 95\% CI 1.23 to 11.61); their patients would participate in lifestyle modification services (aOR 2.29, 95\% CI 1.02 to 5.15); and their patients understood the concept of being at high risk and adhere to medications (aOR 2.00, 95\% CI 0.88 to 4.58). High assessors were more likely to take a longer time with their patients explaining ACVDR (aOR 3.95, 95\% CI 1.33 to 11.7). High assessment rates were less likely among GPs who agreed it was difficult to opportunistically assess ACVDR during routine consultations (aOR 0.42, 95\% CI 0.16 to 1.11) and also agreed that the ACVDR score estimated risk over too long a time (aOR $0.24,95 \%$ CI 0.07 to 0.78 ). Clinical practice software, inbuilt calculator availability and the use of these tools were not associated with assessment rates. Views regarding lack of incentives, funding and effective lifestyle modification services were also not associated with assessment rates (table 4).

\section{Perceived barriers and enablers to ACVDR assessment}

Almost $80 \%$ of GPs agreed better consumer education for patients could increase uptake, and that nurses could prescreen eligible patients prior to their GP appointment (table 5), with $71 \%$ also believing practice nurses could undertake assessment themselves. Three-quarters felt computer prompt reminders would be helpful. Over $70 \%$ felt a recall of all eligible patterns in their registry would be effective, and that adequate funding or incentives would increase uptake. Sixty-five per cent agreed dedicated assessment time in their schedule would increase assessments, and $62 \%$ reported the best way to undertake assessments was opportunistically. The questions relating to enablers can also be found in table 5 .

\section{Sensitivity analysis}

The analyses examining associations between assessment rate and GP characteristics, knowledge attitude and beliefs were repeated with the binary outcome variable redefined as 'high/moderate assessors' (risk scores assessed in $\geq 60 \%$ eligible patients, $70 \%$ of GPs) versus low assessors $(<60 \%$ eligible patients, $30 \%$ of GPs) and did not differ materially from the main analyses.

\section{DISCUSSION}

This study on self-reported practices of regional GPs on CVD risk showed the vast majority use ACVDR assessment, but less than half assess $\geq 80 \%$ of eligible patients, and 1 in 10 is assessing ACVDR in a low proportion of their patients $<20 \%$ ) or not at all. GPs who are older, have a lower knowledge of ACVDR guidelines and/or believe 


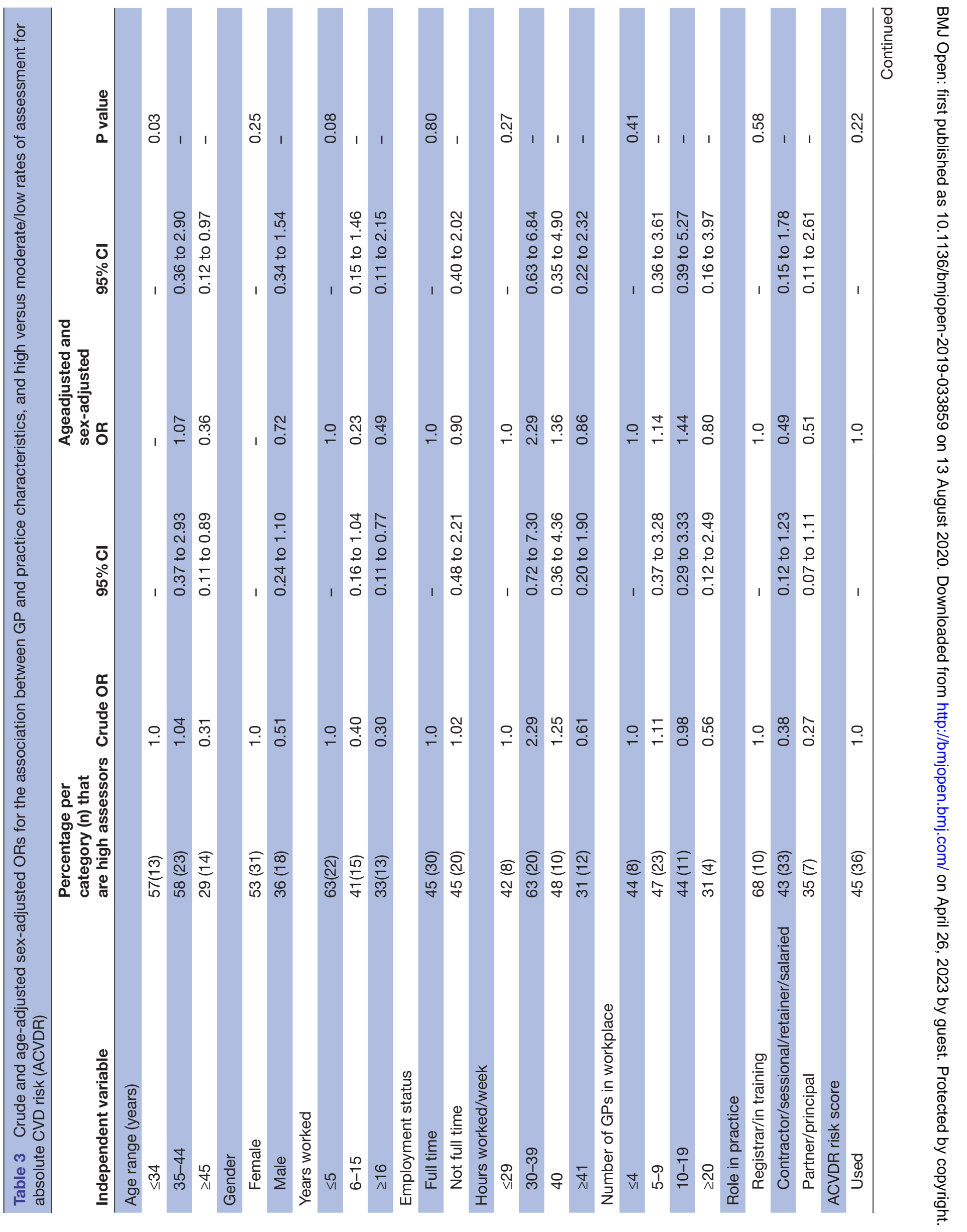




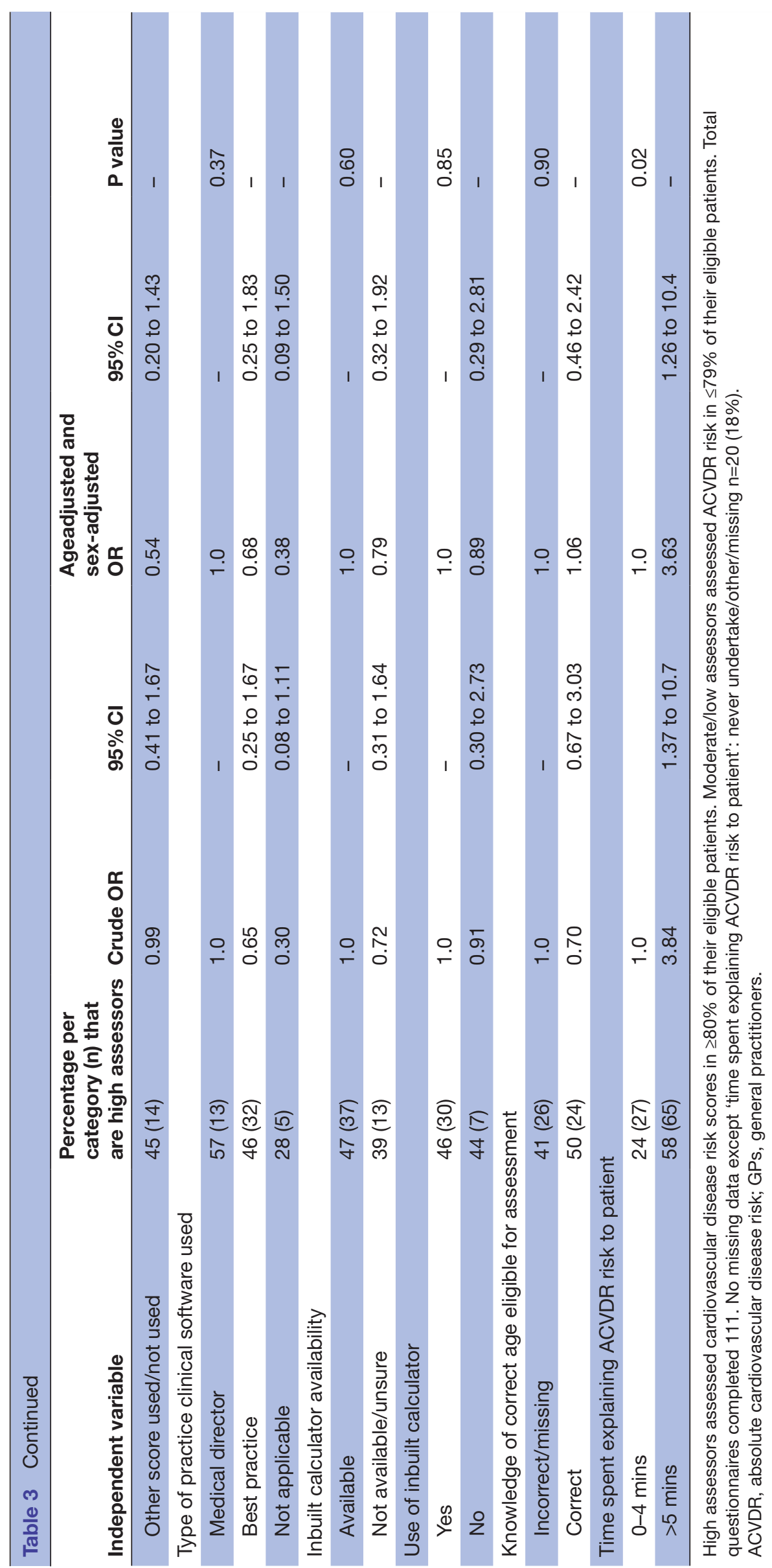

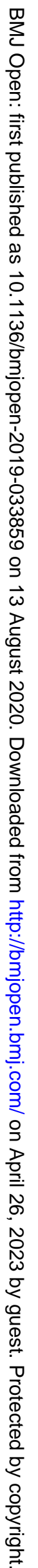


Table 4 GP knowledge, attitudes and beliefs in relation to absolute CVD risk (ACVDR) assessment: percentage agreeing with statements overall, and agreeing by ACVDR assessment rates (high vs moderate/low assessors), and associated crude and age-adjusted and sex-adjusted ORs

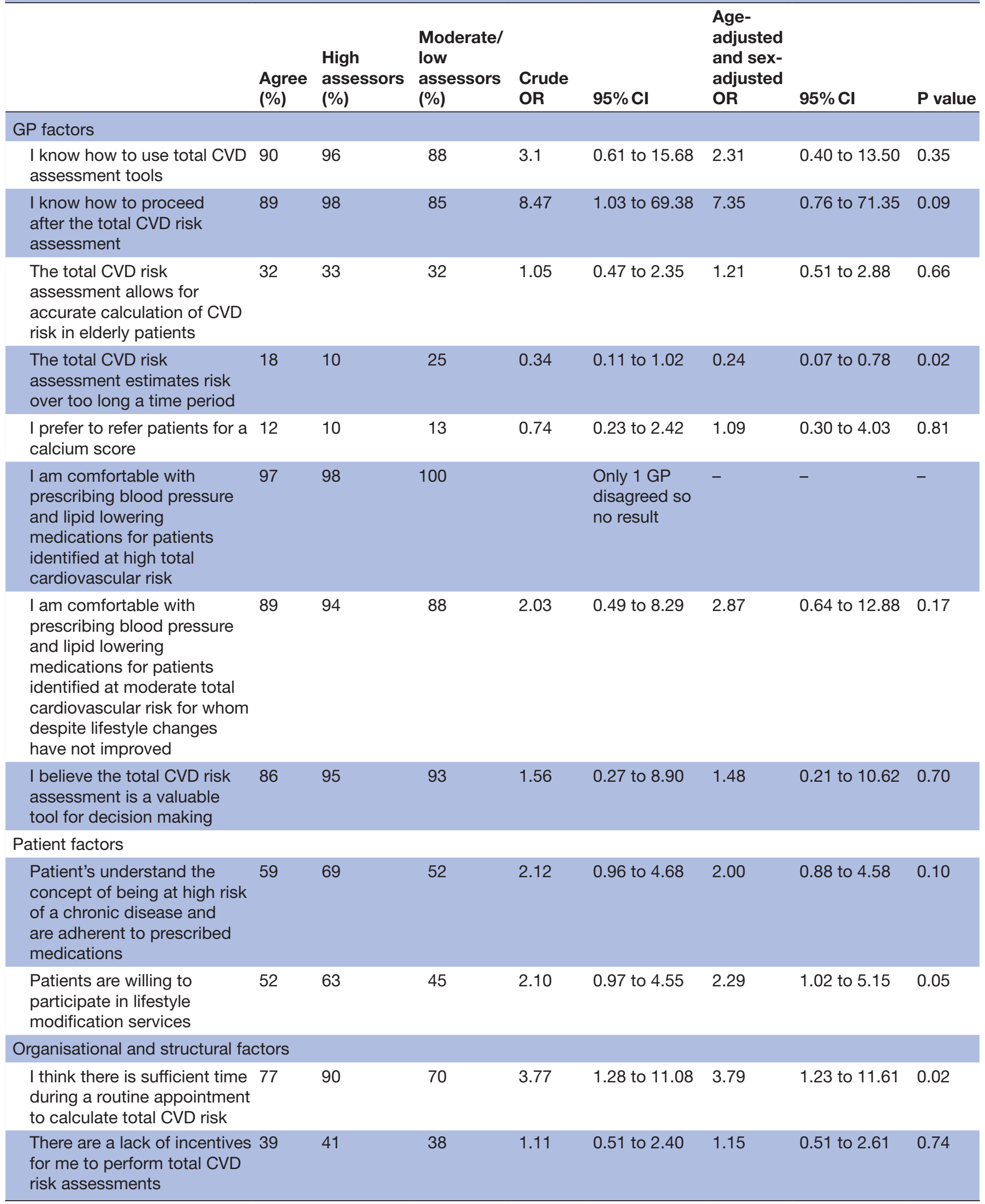




\begin{tabular}{|c|c|c|c|c|c|c|c|c|}
\hline & $\begin{array}{l}\text { Agree } \\
(\%)\end{array}$ & $\begin{array}{l}\text { High } \\
\text { assessors } \\
(\%)\end{array}$ & $\begin{array}{l}\text { Moderate/ } \\
\text { low } \\
\text { assessors } \\
(\%)\end{array}$ & $\begin{array}{l}\text { Crude } \\
\text { OR }\end{array}$ & $95 \% \mathrm{Cl}$ & $\begin{array}{l}\text { Age- } \\
\text { adjusted } \\
\text { and sex- } \\
\text { adjusted } \\
\text { OR }\end{array}$ & $95 \% \mathrm{Cl}$ & $P$ value \\
\hline $\begin{array}{l}\text { Total CVD risk assessments } \\
\text { are difficult to incorporate } \\
\text { opportunistically during } \\
\text { patient consultations }\end{array}$ & 26 & 16 & 35 & 0.36 & 0.14 to 0.91 & 0.42 & 0.16 to 1.11 & 0.08 \\
\hline $\begin{array}{l}\text { Total cholesterol and } \\
\text { HDL results are often } \\
\text { not available for patients } \\
\text { requiring total CVD risk } \\
\text { assessment }\end{array}$ & 20 & 18 & 18 & 1.00 & 0.38 to 2.66 & 0.93 & 0.33 to 2.58 & 0.88 \\
\hline
\end{tabular}

High assessors assessed cardiovascular disease (CVD) risk scores in $\geq 80 \%$ of their eligible patients. Moderate/low assessors assessed ACVDR in $\leq 79 \%$ of their eligible patients. Total questionnaires completed $n=111$. Data were incomplete in two (2\%) patients, except for the question 'I believe the total CVD risk assessment is a valuable tool for decision making', which had nine (8\%) missing. Percentage agreeing=proportion of GPS who 'strongly agreed', 'agreed' or 'somewhat agreed'/total GPs who responded × 100 .

GPs, general practitioners.

their patients lack understanding of CVD risk have lower assessment rates. GPs with higher assessment rates are more likely to report having sufficient time in consultations and spend more time explaining ACVDR risk to their patients. There was high agreement among GPs that actions that would enable ACVDR assessment were better patient education, nurse-led assessment and computerreminder prompts.

Table 5 Potential enablers to increase absolute CVD risk assessments: percentage of GPs agreeing with statements

\begin{tabular}{|c|c|}
\hline & $\begin{array}{l}\text { Agree } \\
(\%)\end{array}$ \\
\hline $\begin{array}{l}\text { Better consumer education for patients about having their total CVD risk checked could increase uptake of } \\
\text { assessments. }\end{array}$ & 86 \\
\hline $\begin{array}{l}\text { Patients eligible for a total CVD risk assessment could be prescreened by the practice nurse prior to their GP } \\
\text { appointment. }\end{array}$ & 86 \\
\hline Computer prompt reminders for patients due for a total CVD risk assessment could increase uptake. & 82 \\
\hline Practice nurses are well suited to perform total CVD risk assessments. & 78 \\
\hline $\begin{array}{l}\text { A recall of all eligible patients in the GP registry due for a total CVD assessment would be an effective method of } \\
\text { increasing uptake. }\end{array}$ & 77 \\
\hline If I was allocated dedicated screening time in my schedule, I could complete more total CVD risk assessments. & 73 \\
\hline Total CVD risk assessments performed within a workplace setting could be an effective means of increasing uptake. & 63 \\
\hline If appointment time slots were increased, this could enable more total CVD risk assessments. & 61 \\
\hline
\end{tabular}

Total $n=111,8 \%-10 \%$ missing for each statement. Percentage agreement=proportion of GPs who 'strongly agreed', 'agreed' or 'agreed somewhat'/total GPs who responded × 100 .

CVD, cardiovascular disease; GPs, general practitioners. 
There are limited data published in Australia and internationally on ACVD assessment coverage in general practice. A 2012 survey of 806 physicians across 12 European countries found $85 \%$ reported following at least one set of CVD risk guidelines, but there was no indication as to what proportion of their eligible patients underwent risk assessment. ${ }^{13}$ The 2006 National (USA) Research network Survey on CVD risk assessment found 92\% of GPs reported 'usually' or 'always' assessing for CVD risk factors; however, only $17 \%$ used a risk calculator. ${ }^{19}$ Our study is consistent with these findings in that although the majority of GPs were aware of the absolute CVD risk concept, less than half had heard of the NVDPA guidelines and $11 \%$ were unaware CVD risk assessment should be carried out in all eligible patients. However, in our study, around $90 \%$ of GPs reported using a risk calculator of some kind. To our knowledge, our study is the first in Australia on self-reported assessment rates for CVD risk among individual GPs, finding they are relatively low. Although the AusHEART study reported almost $90 \%$ of GPs provided an estimate of absolute risk, the provision of this estimate was a mandatory part of the protocol. ${ }^{12}$

A lack of knowledge by GPs is known to be a barrier to the use of guidelines. The EURIKA study reported $12 \%$ of GPs did not use guidelines, of whom $28 \%$ cited 'not knowing the guidelines' as the reason why. ${ }^{13}$ A study of 25 Australian GPs reported that those not familiar with the guidelines or use of the tools did not calculate CVD risk. ${ }^{15}$ In our study, incorrect answers on patient eligibility and assessment intervals for risk scoring were associated with lower assessment rates. Those who knew how to use and proceed after using the guidelines had high assessment rates. Previous studies have documented that a small proportion of GPs still base their assessment of CVD risk on a single risk factor and this is also consistent with our findings. ${ }^{20}$ The difference between the number of GPs who had heard of the ACVD risk guidelines (96\%) and who had heard of the NVDPA $(45 \%)$ is perhaps not unexpected. While the NVDPA guidelines form the basis of CVD risk assessment in Australia, GPs may get advice from preventive health guidelines such as the RACGP Red Book, which includes the NVDPA algorithm.

Patient knowledge and behaviour is also known to influence a GP's assessment of CVD risk. A systematic review on GP perspectives of CVD prevention found lack of patient motivation for behavioural change and a capacity for lifestyle change to be important practice influencers. ${ }^{9}$ Our study revealed this too, and most GPs believed better consumer education for patients would increase CVD risk assessment.

Time availability is also known to be a significant factor affecting ACVDR assessment and is consistent with our findings that GPs who felt there was sufficient time for assessment had higher assessment rates. ${ }^{13} 21$

There was high agreement on a number of possible strategies to increase assessment. These included preassessment of patients prior to their appointment, which could be nurse led, and recall of known high-risk patients not appropriately treated. Nurse-led interventions have been shown to be successful in cardiovascular care. ${ }^{22}$

To encourage increased uptake of ACVDR, the Australian government introduced a Heart Health Assessment, which requires ACVDR assessment, to the Medicare Benefits Schedule (MBS) in April 2019. ${ }^{23}$ While our study preceded the new MBS Heart Health Assessment, this new MBS item addresses some enablers identified in our study that may increase ACVDR assessment such as preassessment by practice nurses and a modest financial incentive ${ }^{23}$ However, our results indicate that consumer education needs to accompany this new item.

This study was limited to GP practices in Queensland with opportunistic sampling of a small percentage of GPs predominantly from the Sunshine Coast, which itself has different demographics to other areas within Australia. Therefore, its applicability to other regions and countries should be considered. Our study also relies on GPs self-reporting rather than objective measurements of behaviour, which is an inherent problem with questionnaire-based surveys and should be taken into account when interpreting the results. It is also worth noting that apart from age eligibility for screening, our survey measured GPs perceived rather than factual knowledge of CVD risk assessment. Another point is that there is likely bias in the self-reported assessment rates (probably overestimated), and hence these may not be generalisable to the GP population. However, representativeness is not necessary for valid internal comparisons, that is, our estimates of the associations between factors (GPs knowledge, attitudes and beliefs) and assessment rates are internally valid, and thus also our conclusions regarding barriers and enablers. We did not define the eligible population for ACVDR assessment in the survey as we wished to understand GPs knowledge on this topic. Only $43 \%$ answered correctly on the age patients became eligible for assessment. It is therefore likely that a proportion of GPs may be assessing the incorrect patients. However, we would not expect this fact to alter the conclusions of our study given it was not the purpose of the study to assess what proportion of eligible patients are actually assessed in primary care (this would obviously require a different study design), rather the purpose was to better understand enablers and barriers to assessment (by examining factors associated with assessing/not assessing patients deemed eligible for assessment).

\section{CONCLUSION}

This study showed that although the majority of GPs report using the ACVDR calculator when undertaking a CVD risk assessment, there is a need to increase the actual proportions of eligible patients undergoing ACVDR assessment. This might be achieved by improving GP assessment practices, including through increasing GP and patient knowledge of CVD risk, nurse-led assessment and providing sufficient time for GP ACVDR assessment. Addressing these issues could lead to increased 
identification and treatment of at-risk patients and the reduction of CVD.

\section{Author affiliations}

${ }^{1}$ National Centre for Epidemiology and Population Health, Canberra, Australian Capital Territory, Australia

${ }^{2}$ Department of Cardiology, Sunshine Coast University Hospital, Sunshine Coast, Queensland, Australia

Acknowledgements The authors would like to acknowledge the help of Rachelle Foreman of the National Heart Foundation of Australia, Dr John Harper, Robb Major and Deidre Ballinger of Central Queensland, Wide Bay and Sunshine Coast Primary Health Network, in the design of the survey questionnaire.

Contributors All authors made substantial contributions to the conception or design of the work; the acquisition, analysis and interpretation of data for the work; $\mathrm{KG}$ drafted the work and gave final approval of the version to be published. All authors revised it critically for important intellectual content and gave final approval of the version to be published. All authors agree to be accountable for all aspects of the work in ensuring that questions related to the accuracy or integrity of any part of the work are appropriately investigated and resolved.

Funding The authors have not declared a specific grant for this research from any funding agency in the public, commercial or not-for-profit sectors.

Competing interests None declared.

Patient consent for publication Not required.

Ethics approval The survey was approved by the human research ethics committees of the Royal Brisbane and Women's Hospital (HREC/17/QRBW/98) and the Australian National University (Protocol 2017/600).

Provenance and peer review Not commissioned; externally peer reviewed. Data availability statement № data are available. № additional data available.

Open access This is an open access article distributed in accordance with the Creative Commons Attribution Non Commercial (CC BY-NC 4.0) license, which permits others to distribute, remix, adapt, build upon this work non-commercially, and license their derivative works on different terms, provided the original work is properly cited, appropriate credit is given, any changes made indicated, and the use is non-commercial. See: http://creativecommons.org/licenses/by-nc/4.0/.

ORCID iD

Kim Greaves http://orcid.org/0000-0002-5511-2486

\section{REFERENCES}

1 Murray CJL, Vos T, Lozano R, et al. Disability-adjusted life years (DALYs) for 291 diseases and injuries in 21 regions, 1990-2010: a systematic analysis for the global burden of disease study 2010. Lancet 2012;380:2197-223.

2 Lozano R, Naghavi M, Foreman K, et al. Global and regional mortality from 235 causes of death for 20 age groups in 1990 and 2010: a systematic analysis for the global burden of disease study 2010 . Lancet 2012;380:2095-128.

3 Australian Health Ministers' Advisory Council AG C. National strategic framework for chronic conditions, 2017.

4 Liu K, Daviglus ML, Loria CM, et al. Healthy lifestyle through young adulthood and the presence of low cardiovascular disease risk profile in middle age: the coronary artery risk development in (young) adults (cardia) study. Circulation 2012;125:996-1004.

5 Jackson R, Lawes C, Bennett D, et al. Treatment with drugs to lower blood pressure and blood cholesterol based on an individual's absolute cardiovascular risk. The Lancet 2005;365:434-41.

6 Sundström J, Jackson R, Woodward M, et al. Blood pressure lowering and cardiovascular risk - Authors' reply. Lancet 2014;384:1746-7.

7 Alliance NVDP. Guidelines for the management of absolute cardiovascular disease risk, 2012.

8 Alliance NVDP. Australian absolute cardiovascular disease risk calculator, 2012. Available: https://www.cvdcheck.org.au/ [Accessed 13 Nov 19].

9 Banks E, Crouch SR, Korda RJ, et al. Absolute risk of cardiovascular disease events, and blood pressure- and lipid-lowering therapy in Australia. Med J Aust 2016;204:320.

10 Peiris D, Usherwood T, Panaretto K, et al. Effect of a computerguided, quality improvement program for cardiovascular disease risk management in primary health care: the treatment of cardiovascular risk using electronic decision support cluster-randomized trial. Circ Cardiovasc Qual Outcomes 2015;8:87-95.

11 Ju I, Banks E, Calabria B, et al. General practitioners' perspectives on the prevention of cardiovascular disease: systematic review and thematic synthesis of qualitative studies. BMJ Open 2018;8:e021137.

12 Heeley EL, Peiris DP, Patel AA, et al. Cardiovascular risk perception and evidence--practice gaps in Australian general practice (the AusHEART study). Med J Aust 2010;192:254-9.

13 Dallongeville J, Banegas JR, Tubach F, et al. Survey of physicians' practices in the control of cardiovascular risk factors: the EURIKA study. Eur J Prev Cardiol 2012;19:541-50.

14 Kirby M, Machen I. Impact on clinical practice of the joint British societies' cardiovascular risk assessment tools. Int J Clin Pract 2009;63:1683-92.

15 Bonner C, Jansen J, McKinn S, et al. General practitioners' use of different cardiovascular risk assessment strategies: a qualitative study. Med J Aust 2013;199:485-9.

16 Patel A, Peiris D. How to treat: cardiovascular risk assessment and management. Australian Doctor 2014:23-30.

17 Torley D, Zwar N, Comino EJ, et al. GPs' views of absolute cardiovascular risk and its role in primary prevention. Aust Fam Physician 2005;34:503-4.

18 Mcavoy BR, Fulcher GR, Amerena JV, et al. An evidence based clinical aid for cardiovascular disease--what do GPs think? Aust Fam Physician 2005;34:297-8.

19 Eaton CB, Galliher JM, McBride PE, et al. Family physician's knowledge, beliefs, and self-reported practice patterns regarding hyperlipidemia: a national research network (NRN) survey. J Am Board Fam Med 2006;19:46-53.

20 Graham IM, Stewart M, Hertog MGL, et al. Factors impeding the implementation of cardiovascular prevention guidelines: findings from a survey conducted by the European Society of cardiology. Eur J Cardiovasc Prev Rehabil 2006;13:839-45.

21 Sposito AC, Ramires JAF, Jukema JW, et al. Physicians' attitudes and adherence to use of risk scores for primary prevention of cardiovascular disease: cross-sectional survey in three world regions. Curr Med Res Opin 2009;25:1171-8.

22 Connolly SB, Kotseva K, Jennings C, et al. Outcomes of an integrated community-based nurse-led cardiovascular disease prevention programme. Heart 2017;103:840-7.

23 MOwDoH AG. New MBS items for heart health check: item 699 and 1772019: MBS online website.Department of health Ag, 2019. Available: http://www.mbsonline.gov.au/internet/mbsonline/ publishing.nsf/Content/2E3497ACC7C00A68CA2583CA00171F72/\$ File/Factsheet\%20-\%20Heart\%20Health\%20Check.pdf. 